\section{»ästhetische dermatologie}

\& kosmetologie

\section{inhalt $06 \cdot 2016$}

editorial

03 Merry Christmas!

Matthias Herbst

top thema

08 Lasertherapie bei Onychomykose

„Fußpflege ist gefährlicher als Lasertherapie“ Interview mit Gerald Messer

derma aktuell

12 Überraschende Fitness-Studie

Fett trotz App

14 Möglicher Zusatznutzen

Tacrolimus unterstützt UV-Therapie bei Kindern mit Vitiligo

16 Psychodontie

Gesunde Zähne - glücklicher Mensch?

gastbeitrag

18 Humane Papillomviren

Warzen - wann und wie behandeln?

Sabine Gisela Plötz, Christina Kellerer, Daniel Kneißl, Johannes Ring

22 Basisdiagnostik

Kosmetologische Diagnostik der Haare, Nägel und Haut

Hans Schulz, Max Hundeiker, Jürgen Kreusch praxis \& geld

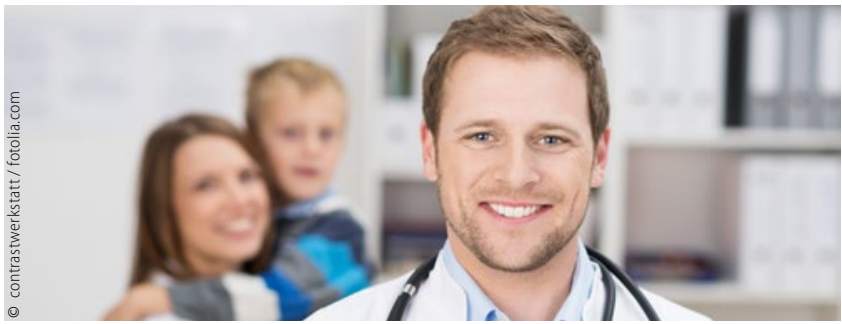

37 Praxisführung

Rechtliche Aspekte bei der Niederlassung als Dermatologe Gwendolyn Gemke

40 Transparenz für Arzt und Patient

Der Behandlungsvertrag Kai Jochen Friedrich

42 Tipps für das ganze Praxisteam

Gekonnt reagieren, wenn der Patient wütend ist

prisma

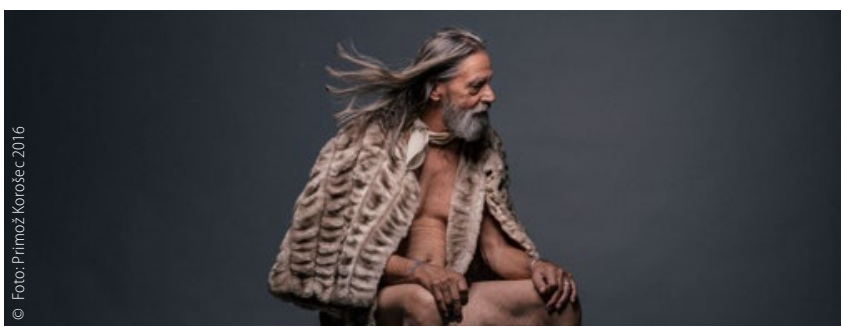

47 Frankfurter Schirn präsentiert „Ulay Life-Sized“ Weg eines permanenten Werdens

rubriken

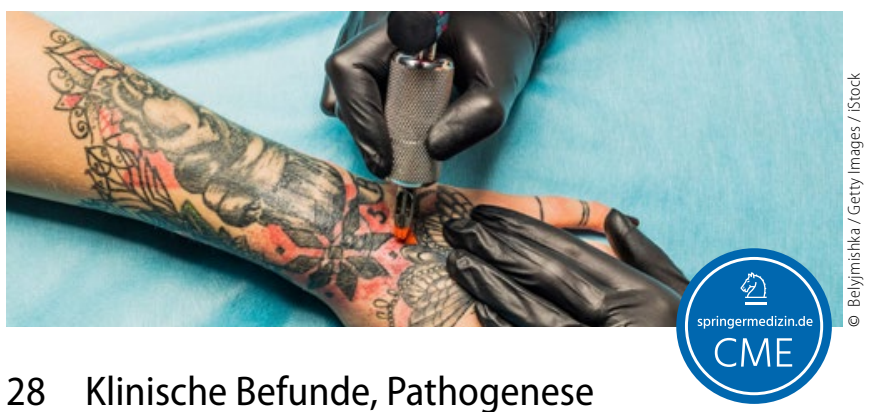

6 kurz \& knapp

43 infopharm

50 beirat

51 termine | impressum | kontakt

ADK

49 ADK-Beitrittsantrag

Gunnar Wagner, Volker Meyer, Michael Sachse

\title{
35 CME-Fragebogen
}

